\title{
Erratum to: Differences in TGF- $\beta 1$ signaling and clinicopathologic characteristics of histologic subtypes of gastric cancer
}

Kyung Ho Pak ${ }^{1,3}$, Dong Hoon Kim², Hyunki Kim ${ }^{4}$, Do Hyung Lee ${ }^{5}$ and Jae-Ho Cheong ${ }^{5,6,7,8^{*}}$

\section{Erratum}

Unfortunately, the original version of this article [1] contained an error in Fig. 2. Within this figure, the annotations for "High TGFb1" and "Low TGFb1" were the wrong way around. This has been corrected in the original article and is also included correctly below.

\footnotetext{
Author details

'Department of Surgery, Hallym University Medical Center, Hwasung, Korea. ${ }^{2}$ Department of Pathology, Hallym University Medical Center, Hwasung, Korea. ${ }^{3}$ Department of Medicine, Yonsei University Graduate School, Seoul, Korea. ${ }^{4}$ Department of Pathology, Yonsei University College of Medicine, Seoul, Korea. ${ }^{5}$ Depatment of Surgery, Yonsei University College of Medicine, 50-1 Yonsei-ro, Seoul, Seodaemun-gu 120-752, Korea. ${ }^{6}$ Department of Biochemistry \& Molecular Biology, Yonsei University College of Medicine, Seoul, Korea. ${ }^{7}$ Brain Korea 21 PLUS Project for Medical Science, Yonsei University College of Medicine, Seoul, Korea. ${ }^{8}$ Open NBI Convergence Technology Research Laboratory, Yonsei University College of Medicine, Seoul, Korea.
}

Received: 8 February 2016 Accepted: 8 February 2016

Published online: 15 February 2016

\section{Reference}

1. Pak KH, Kim DH, Kim H, Lee DH, Cheong JH. Differences in TGF- $\beta 1$ signaling and clinicopathologic characteristics of histologic subtypes of gastric cancer. BMC Cancer. 2016;16:60. doi:10.1186/s12885-016-2091-x.

\footnotetext{
* Correspondence: jhcheong@yuhs.ac

${ }^{5}$ Depatment of Surgery, Yonsei University College of Medicine, 50-1 Yonsei-ro, Seoul, Seodaemun-gu 120-752, Korea

${ }^{6}$ Department of Biochemistry \& Molecular Biology, Yonsei University College of Medicine, Seoul, Korea
}

Submit your next manuscript to BioMed Central and we will help you at every step:

- We accept pre-submission inquiries

- Our selector tool helps you to find the most relevant journal

- We provide round the clock customer support

- Convenient online submission

- Thorough peer review

- Inclusion in PubMed and all major indexing services

- Maximum visibility for your research

Submit your manuscript at

www.biomedcentral.com/submit \section{.}




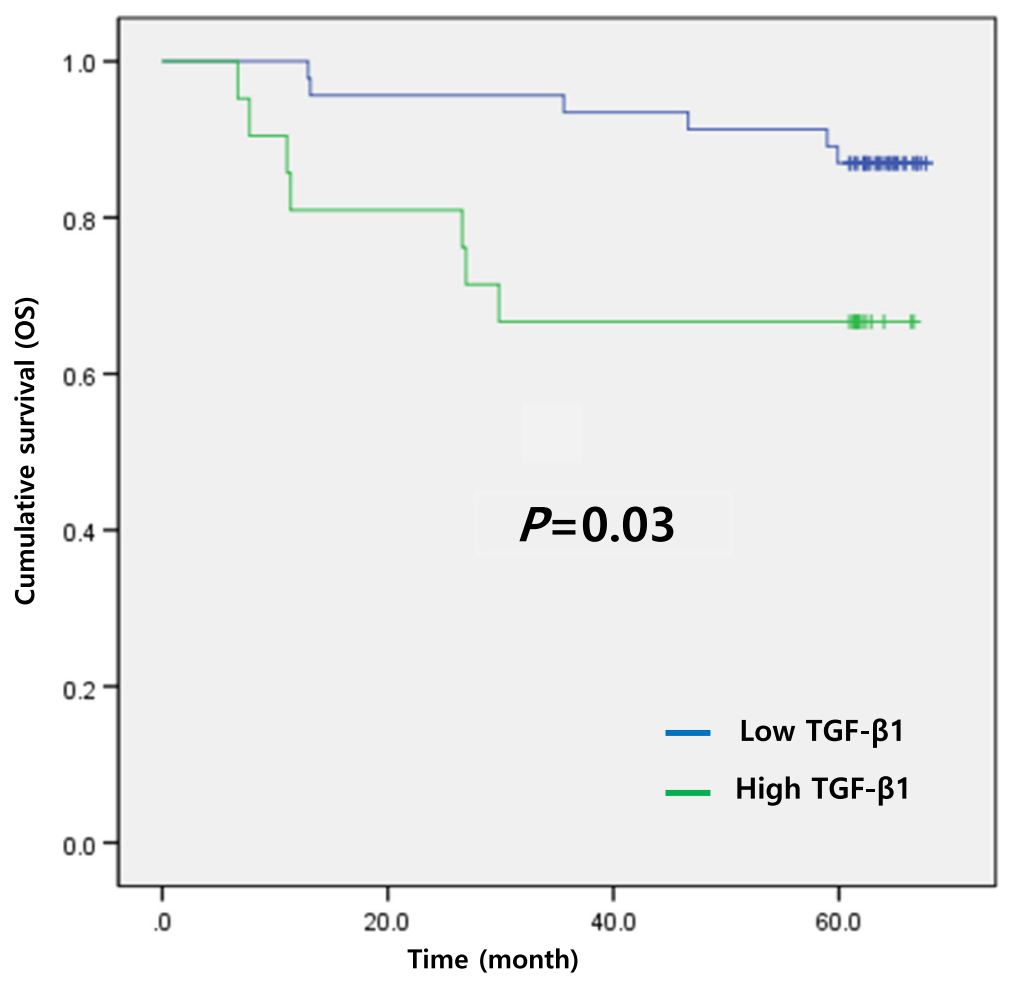

Fig. 2 